\title{
Simulation Study on Dynamic Characteristic of Marine Elevator
}

\author{
Ji'ai Xue, Weiping Ouyang*, Yannan Du and Huiqing Ouyang \\ No. 915 Jinshajiang Road Shanghai, China \\ ${ }^{*}$ Corresponding author
}

\begin{abstract}
Marine passenger elevator is as a new type of special equipment, which has been extensively used in all kinds of marine and marine engineering development equipment. The accelerations between the simulation and test of each working conditions is different, but the trend of change is basically consistent. The simulation results could serve as reference for marine elevator structure design. During simulation, the gap between the guide and boot is not taken into consideration, which may be the main cause of the difference. It is clearly seen that when the rolling cycle is constant. The angle of rolling is increased, whose value is obviously increased. The maximum possible acceleration under due to rolling is $1.665 \mathrm{~m} / \mathrm{s}^{2}$ under normal condition, and that due to pitching is reduced to 0.939 $\mathbf{m} / \mathbf{s}^{2}$. The maximum value caused by the combination of rolling and pitching is $1.596 \mathrm{~m} / \mathrm{s}^{2}$. The maximum value under abnormal working condition is $1.734 \mathrm{~m} / \mathrm{s}^{2}$, which is slightly more than that under normal working condition. The safety factor of the prototype is at least 1.7 times higher than that of the landed elevator.
\end{abstract}

Keywords-marine elevator; dynamic characteristic; simulation

\section{INTRODUCTION}

Marine passenger elevator is as a new type of special equipment, which has been extensively used in all kinds of marine and marine engineering development equipment[1-2]. The landed elevator is more mature than the marine elevator in the technological field. There are great differences in the application environment and design requirements of the marine elevator compared with the landed elevator[3-5]. Landed elevator is generally fixed with building. Apart from earthquakes, the vibration and sloshing of buildings are usually not taken into account. While the marine elevator is operating in a river or sea environment, it still needs to meet the requirements of normal use during the voyage of the ship. The fluctuation in the ship's operation has a significant impact on the mechanical strength and safety reliability of the elevator, and the structural design should not be ignored. During the voyage of the ship in the wind and waves, the oscillation is mainly composed of rolling, pitching, baying, heaving, swinging, and so on. Among them, rolling and pitching have relatively great influence on the normal operation of the marine elevator. It is necessary to check the dynamic response of the marine elevator under rolling, pitching or coupling conditions[6-7].

It is mainly studied the dynamic characteristics on simulation and test under different working conditions of marine elevator, which is used to predict the acceleration of marine elevators under abnormal condition and to improve the safety assessment method of the marine elevator.

\section{ESTABLISHMENT OF DYNAMIC MODEL}

The conditions for the normal operation of the marine elevator are shown: Rolling is controlled within $\pm 10^{\circ}$, and pitching is controlled within $\pm 7^{\circ}$ per $\mathrm{CB} / \mathrm{T}$ 3567. The cycles are $10 \mathrm{~s}$ and $7 \mathrm{~s}$, respectively. According to "Rules for lifting appliances of ships and offshore installations", rolling is within $\pm 22.5^{\circ}$, and pitching is within $\pm 7.5^{\circ}$. The cycles are $10 \mathrm{~s}$ and $7 \mathrm{~s}$, and the heave amplitude is 0.0125 times length of the ship. Marine traction machine room less passenger elevator is utilized to experiments. Elevator car size is $1600 \times 1500 \times 2360$ $\mathrm{mm}$, and the shaft size is $2200 \times 2350 \times 11000 \mathrm{~mm}$. The number of layers is four. The middle compartment door is employed. The rated speed is $1 \mathrm{~m} / \mathrm{s}$, and limit speed is $1.37 \mathrm{~m} / \mathrm{s}$. During the experiment, the swing table is driven by two inverter motors through the linkage mechanism. The swing table is composed of the inner and outer frame, and the inner frame is exerted the rolling excitation, and the external frame is exerted the pitching excitation. The rolling and pitching are within $10^{\circ}$ and $7.5^{\circ}$, respectively. The cycles are $10 \mathrm{~s}$ and $7 \mathrm{~s}$ per relevant standard, respectively. The lift height is $8.4 \mathrm{~m}$, and the elevator operates twice continuously between the first and fourth floor to test the acceleration during the elevator operation. The EVA-625 vibration analyzer is placed in the middle of the floor, and the directions are illustrated in Figure I.

Elevator is under no-load condition to measure the car acceleration of $\mathrm{X}, \mathrm{Y}$ and $\mathrm{Z}$ under three kinds of working condition: rolling, pitching, rolling and pitching coupling conditions. Dynamic simulation analysis software ADAMS is used. The dynamic model of marine elevator is established based on the actual elevator sea condition as shown in Figure II.

\section{Results Under NORMAL WORKING CONDITIONS}

The empty elevator at the first floor is selected by the simulation and experiment. The motion of the elevator floor is calculated and measured. The relationships between time and acceleration in $\mathrm{X}$ and $\mathrm{Z}$ direction under rolling, pitching and coupling conditions for simulation and experiment are shown in Figure III-Figure IV. It is clearly seen that the accelerations between the simulation and test of each working conditions is different, but the trend of change is basically consistent. The simulation results could serve as reference for marine elevator structure design. During simulation, the gap between guide and 
boot is not taken into consideration, which may be the main cause of the difference. In addition, the installation of the elevator and other factors may also affect the measured acceleration.

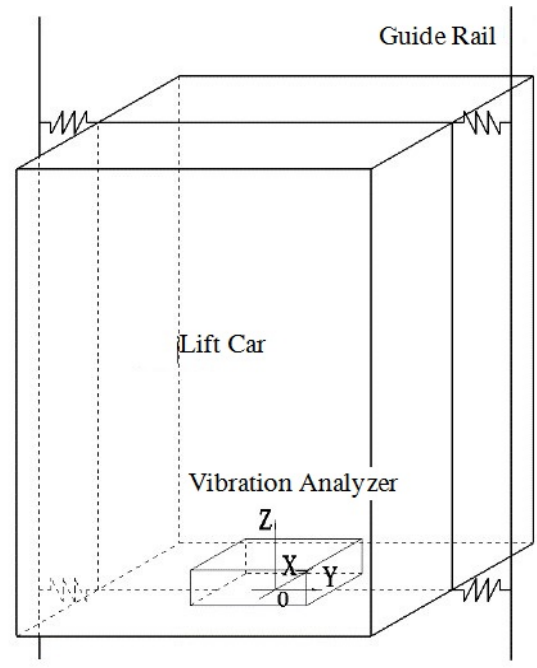

FIGURE I. LAYOUT OF THE SENSOR

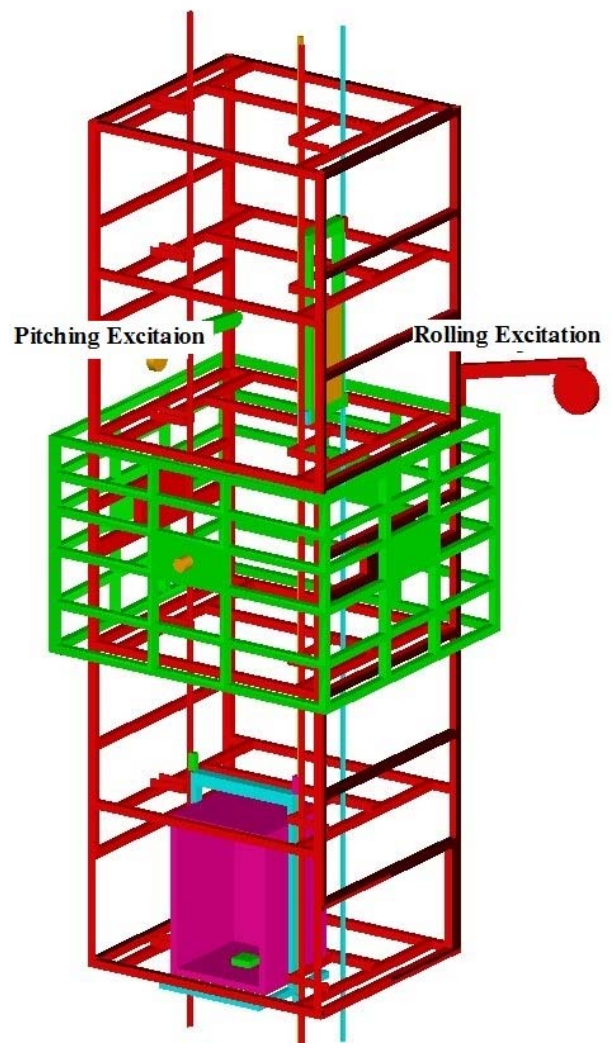

FIGURE II. DYNAMIC MODEL OF SWING TABLE AND ELEVATOR SYSTEM

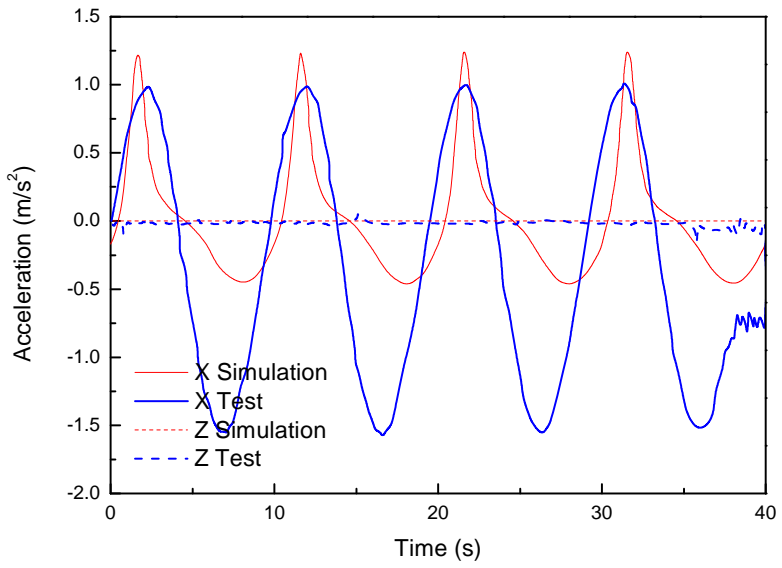

FIGURE III. RELATIONSHIP BETWEEN TIME AND ACCELERATION OF SIMULATION AND TEST CONDITIONS IN X AND Z DIRECTION UNDER ROLLING CONDITION

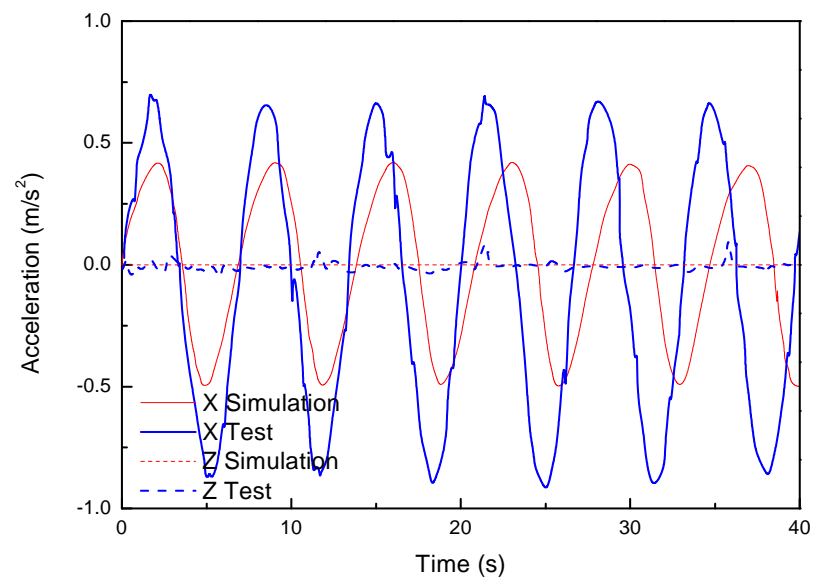

FIGURE IV. RELATIONSHIP BETWEEN TIME AND ACCELERATION OF SIMULATION AND TEST CONDITIONS IN X AND Z DIRECTION UNDER PITCHING CONDITION

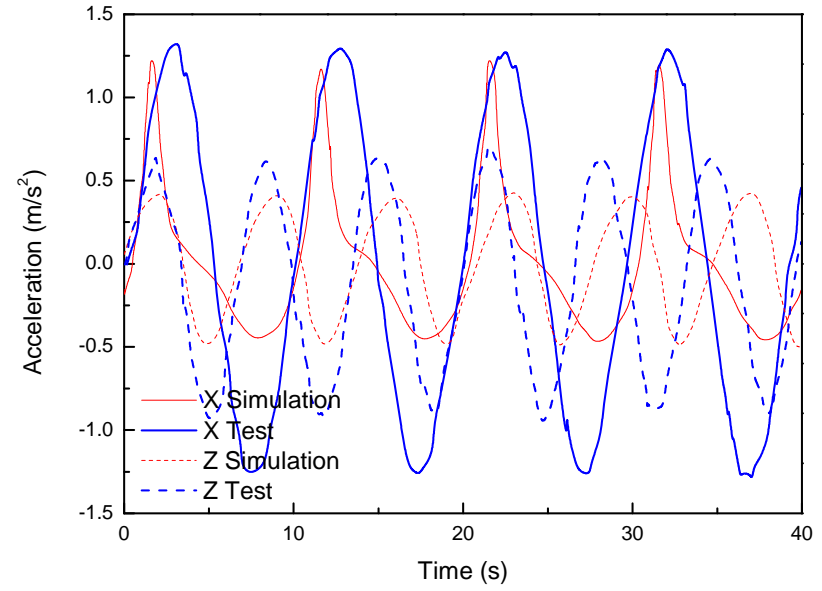

FIGURE V. RELATIONSHIP BETWEEN TIME AND ACCELERATION OF SIMULATION AND TEST CONDITIONS IN X AND Z DIRECTION UNDER COUPLING CONDITION 
The results of simulation and experiment are given in Table 1. It is clearly seen that when the rolling cycle is constant. The angle of rolling is increased, whose value is obviously increased. The maximum possible acceleration due to rolling is $1.665 \mathrm{~m} / \mathrm{s}^{2}$, and that due to pitching is reduced to $0.939 \mathrm{~m} / \mathrm{s}^{2}$. The maximum value caused by the combination of rolling and pitching is $1.596 \mathrm{~m} / \mathrm{s}^{2}$.

\section{RESUlts Under ABNORMAL WORKING CONDITION}

The empty elevator at the first floor is selected by the simulation and experiment. The motion of the elevator floor is calculated and measured. The relationships between time and acceleration in $\mathrm{X}$ and $\mathrm{Z}$ direction under rolling, pitching and coupling conditions by simulation are shown in Fig.6-Fig.8. It is clearly seen that the accelerations of simulation under each working conditions is different. The results of simulation and experiment are shown in Table 2. It is clearly shown that the maximum value under abnormal working condition is 1.734 $\mathrm{m} / \mathrm{s}^{2}$, which is slightly more than that under normal working condition. The safety factor of the prototype is at least 1.7 times higher than that of the landed elevator.

TABLE I. ACCELERATION VALUE OF SIMULATION AND TEST UNDER EACH CONDITION FOR NORMAL CONDITION

\begin{tabular}{|c|c|c|c|c|c|c|}
\hline & \multicolumn{6}{|c|}{ Simulation $\left(\mathrm{m} / \mathrm{s}^{2}\right)$} \\
\hline & \multicolumn{2}{|c|}{ Rolling } & \multicolumn{2}{|c|}{ Pictching } & \multicolumn{2}{|c|}{ Combination } \\
\hline & $\max$ & $\min$ & $\max$ & $\min$ & $\max$ & $\min$ \\
\hline$a_{x}$ & 1.266 & -0.462 & 0 & 0 & 1.238 & -0.472 \\
\hline$a_{z}$ & 0 & 0 & 0.422 & -0.502 & 0.422 & -0.502 \\
\hline \multirow[t]{4}{*}{$a_{x z}$} & 1.266 & -0.462 & 0.422 & -0.502 & 1.308 & -0.689 \\
\hline & \multicolumn{6}{|c|}{ Test $\left(\mathrm{m} / \mathrm{s}^{2}\right)$} \\
\hline & \multicolumn{2}{|c|}{ Rolling } & \multicolumn{2}{|c|}{ Pictching } & \multicolumn{2}{|c|}{ Combination } \\
\hline & $\max$ & $\min$ & $\max$ & $\min$ & $\max$ & $\min$ \\
\hline$a_{x}$ & 1.533 & -1.645 & 0.04 & -0.104 & 1.261 & -1.277 \\
\hline$a_{z}$ & 0.156 & -0.26 & 0.877 & -0.933 & 0.949 & -0.957 \\
\hline$a_{x z}$ & 1.541 & 1.665 & 0.878 & 0.939 & 1.578 & 1.596 \\
\hline
\end{tabular}

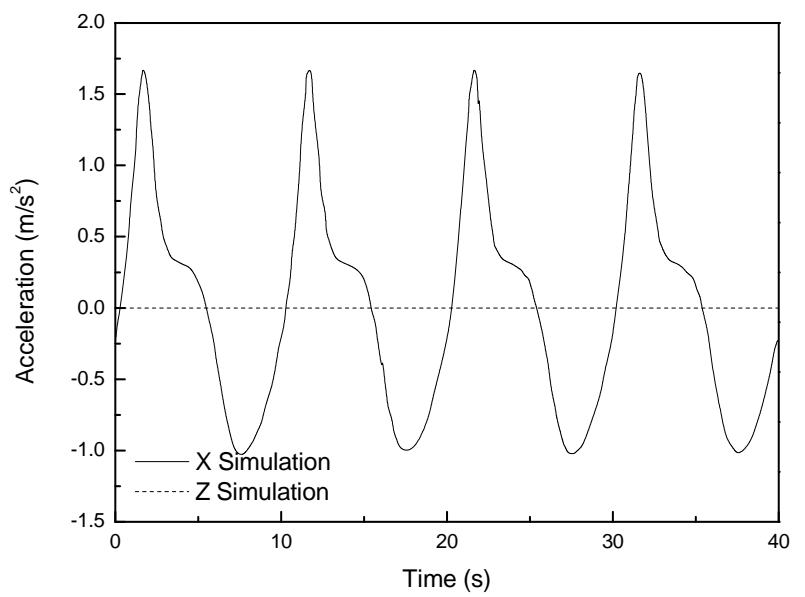

FIGURE VI. RELATIONSHIP BETWEEN TIME AND ACCELERATION OF SIMULATION CONDITION IN X AND Z DIRECTION UNDER ROLLING CONDITION

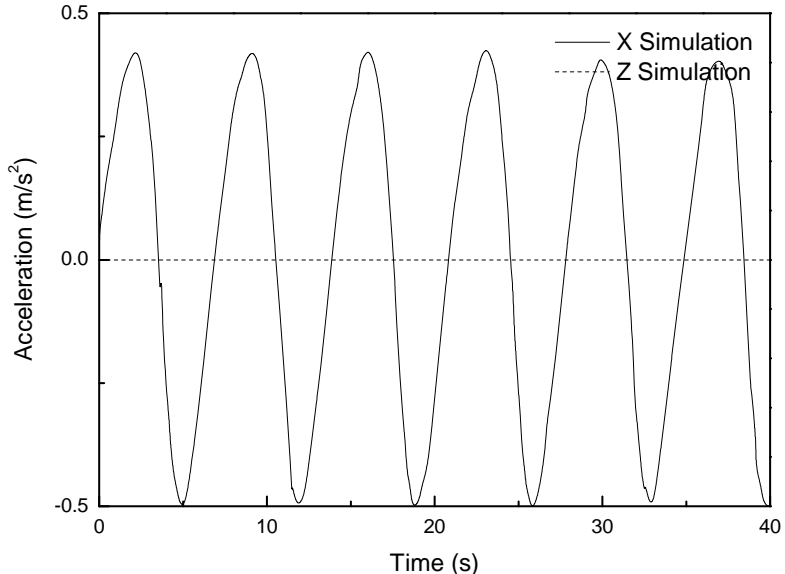

FIGURE VII. RELATIONSHIP BETWEEN TIME AND ACCELERATION OF SIMULATION CONDITION IN X AND Z DIRECTION UNDER PITCHING CONDITION

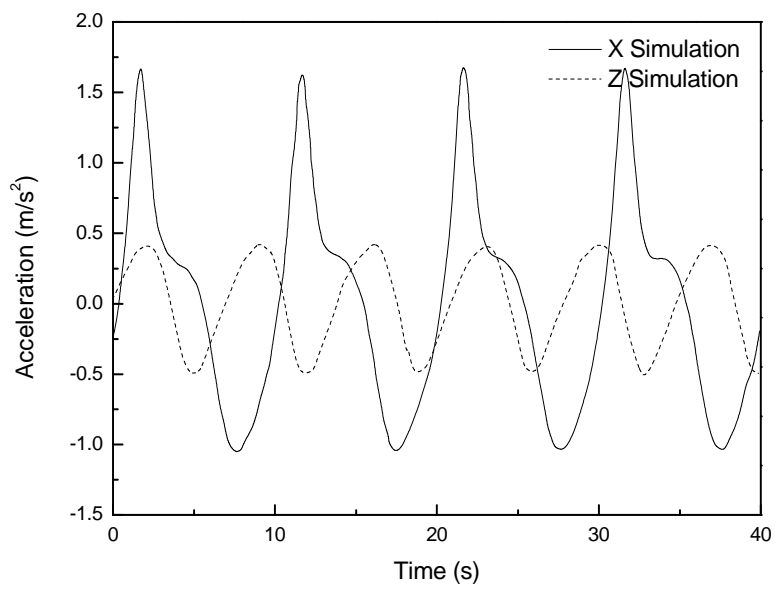

FIGURE VIII. RELATIONSHIP BETWEEN TIME AND ACCELERATION OF SIMULATION CONDITION IN X AND Z DIRECTION UNDER COUPLING CONDITIO

TABLE II. ACCELERATION VALUES OF SIMULATION UNDER EACH CONDITION FOR ABNORMAL CONDITION

\begin{tabular}{|c|c|c|c|c|c|c|}
\hline \multirow{2}{*}{} & \multicolumn{6}{|c|}{ Simulation $\left(\mathbf{m} / \mathbf{s}^{2}\right)$} \\
\cline { 2 - 7 } & \multicolumn{2}{|c|}{ Rolling } & \multicolumn{2}{c|}{ Pictching } & \multicolumn{2}{c|}{ Combination } \\
\cline { 2 - 7 } & $\boldsymbol{m a x}$ & $\min$ & $\max$ & $\min$ & $\max$ & $\min$ \\
\hline$a_{x}$ & 1.682 & -1.093 & 0 & 0 & 1.682 & -1.093 \\
\hline$a_{z}$ & 0 & 0 & 0.422 & -0.502 & 0.422 & -0.502 \\
\hline$a_{x z}$ & 1.682 & -1.093 & 0.422 & -0.502 & 1.734 & 1.203 \\
\hline
\end{tabular}

\section{CONCLUSION}

(1) The accelerations between the simulation and test of each working conditions is different. But the trend of change is basically consistent. The simulation results could be used as reference for marine elevator structure design. During simulation, the gap between guide and boot is not taken into consideration, which may be the main cause of the difference. 
(2) Under normal working condition, it is clearly seen that when the rolling cycle is constant. The angle of rolling is increased, whose value is obviously increased. The maximum possible acceleration due to rolling is $1.665 \mathrm{~m} / \mathrm{s}^{2}$, and that due to pitching is reduced to $0.939 \mathrm{~m} / \mathrm{s}^{2}$. The maximum value caused by the combination of rolling and pitching is $1.596 \mathrm{~m} / \mathrm{s}^{2}$.

(3) It is clearly shown that the maximum value under abnormal working condition is $1.734 \mathrm{~m} / \mathrm{s}^{2}$, which is slightly more than that under normal working condition. The safety factor of the prototype is at least 1.7 times higher than that of the landed elevator.

\section{REFERENCES}

[1] S. L. Li, "Functional design of marine elevator," Ship Engineering, vol. 2, pp. 147-150, February 2010.

[2] X. J. Chen, L. Pang, "Standards and key points for the design of marine,” Cheng Shi Jian She Li Lun Yan Jiu, vol. 10, pp. 3235-3236, October 2015.

[3] T. C. Shen, S. L Li, "Analysis of safety protection function of marine elevator,” Ship Engineering, vol. 2, pp. 147-150, Feberary 2010.

[4] J. L. Zhu, S. L Li, T. C. Shen and Y.J. Chen"Design standard of marine elevator,” Ship Standardization Engineer, vol. 1, pp. 28-29, January 2010.

[5] L.M. Wu, Y.Y. Gong, and X.F. Li, "Dynamic characteristics analysis of vertical vibration of haulage type elevator mechanical system," Machinery Design \& Manufacture, vol. 10, pp. 10-16, June 2007.

[6] M.A. Parameswaran, R. Kalyanakrishnan, "Digital simulation of the dynamic travel characteristics of an electric lift,” Mechanism \& Machine Theory, vol. 14, pp. 309-317, July 1979.

H.C Wu, "Design and simulation of 3-DOF swing platform based on marine elevator,” Machine Tool \& Hydraulics, vol. A247, pp. 102-105, April 2017. . 